\title{
A METAMORFOSE EM ANIMAIS: UM CONTO EUROPEU E UM AFRICANO
}

\author{
Ana Luíza de Oliveira e Silva ${ }^{1}$
}

\section{Resumo}

Obras literárias compõem uma fonte de acesso privilegiada para aspectos culturais. Através de contos que foram, inicialmente, narrados oralmente, elementos ligados ao patrimônio cultural tradicional de um povo, como crenças e lendas, vêm à tona. A relação dos homens com a natureza e o mundo à sua volta é um dos aspectos sobre os quais é possível pensar ao analisar contos da literatura oral. Pelo viés específico da metamorfose, procuramos compreender de que maneira esta faceta da cultura aparece em um conto europeu (provavelmente originado na região da França) e em um africano (narrado na região do Níger). Os enfoques priorizados para a análise dos contos são os seguintes: temas referentes à oralidade, como transmissão e preservação de costumes e tradições; e elementos que tocam a relação dos homens com o mundo natural, com especial atenção para o aparecimento de animais nas transformações.

Palavras-chave: Metamorfose. Oralidade. Contos.

\begin{abstract}
Literary pieces form a privileged source to access cultural aspects. Through orally told tales, some elements of a peoples' cultural heritage, such as beliefs and legends, emerge. The relationship between men, nature and the world around them is one of the aspects we can think of when analyzing the tales of oral literature. Through the specific approach of metamorphosis, we intent to understand the way this cultural facet appears in a European (probably of French origin) and in an African (of the Niger territory) tale. The focuses for the analysis of the tales are: orality themes, such as transmission and preservation of customs and traditions; and elements that refer to the relationship of men with the natural world, with special attention to the appearance of animals in the transformations.
\end{abstract}

Keywords: Metamorphosis. Orality. Folktales.

Eh, despois, não sei, não: acordei - eu tava na casa do veredeiro, era de manhã cedinho. Eu tava em barro de sangue, unhas todas vermelhas de sangue. Veredeiro tava mordido morto, mulher do veredeiro, as filhas, menino pequeno... Eh, jucajucá, atiê, atiuca! Aí eu fiquei com dó, fiquei com raiva. Hum, nhem? Cê fala que eu matei? Mordi mas matei não... Não quero ser preso... Tinha sangue deles em minha boca, cara minha. Hum, saí, andei sozim p’los matos, fora de sentido, influição de subir em árvore, eh, mato é muito grande... Que eu andei, que eu andei, sei quanto tempo foi não. Mas quando que eu fiquei bom de mim outra vez, tava nu de todo, morrendo de fome. Sujo de tudo, de terra, com a boca amargosa, atiê, amargoso feito casca de peroba... Eu tava deitado no alecrinzinho, no lugar. Maria-Maria chegou lá perto de mim... Mecê tá ouvindo, nhem? Tá aperceiando... Eu sou onça, não falei? Axi. Não falei - eu viro onça? Onça grande, tubixaba. (ROSA, 2001, p. 233-234).

\footnotetext{
${ }^{1}$ Mestre em História Social pelo Departamento de História da Faculdade de Filosofia, Letras e Ciência Humanas (FFLCH) da Universidade de São Paulo - USP.

Especialista em Ensino de Línguas Estrangeiras Modernas pelo Departamento Acadêmico de Língua Estrangeiras Modernas (DALEM) da Universidade Tecnológica Federal do Paraná - UTFPR. E-mail analuiza.oliveiras@gmail.com
} 
Nem lembro os quantos momentos que o vento rasgou as velas. Dos pedaços rasgados se formaram peixes que me rodavam sobre a cabeça. Até meus remos foram motivo de feitiço. Sua madeira começou a verdejar, brotaram-lhe folhinhas: os remos se convertiam em árvores. Deixei-lhes na água e, quando os soltei, se afundaram, esquecidos de sua obrigação. Continuei remando com minhas próprias mãos e tanto as usei que, entre os dedos, me nasceram peles sobressalientes. Dentro da água eu sentia as escamas no lugar da pele. Lembrei as palavras do feiticeiro: no mar, serás mar. E era: eu me peixava, cumprindo sentença. (COUTO, 2007, p. 41).

As citações das obras literárias de Guimarães Rosa e Mia Couto - a primeira em contexto brasileiro e a segunda em contexto moçambicano -, trazem à tona a questão da metamorfose de humanos em animais. O tema também se faz presente em diversos outros escritos, tais como os contos de fadas imortalizados em território europeu por autores como Andersen, Perrault e os irmãos Grimm, cujos exemplos mais latentes se referem a metamorfoses que resultam em casamentos, como nas histórias O Rei Sapo, A Bela e a Fera e Branca de Neve e Rosa Vermelha. ${ }^{1}$ De acordo com Robert Darnton, nem sempre os animais se transformavam em humanos, sendo que em alguns contos o matrimônio era efetivado com os animais mantidos em suas formas originais (DARNTON, 1986, p. 55-56). Apesar de tais contos chegarem até nós através de Andersen, Grimm e Perrault, não foram criados por aqueles autores, mas postos por eles na palavra escrita a partir de uma imensa coleta de relatos orais. $^{2}$

A questão da oralidade e de sua relação com a escrita é complexa, sendo que um dos aspectos da discussão a esse respeito toca a dificuldade de se atingir o público da mesma maneira que se atinge com o texto escrito. Uma história contada oralmente não é contada de uma forma única e codificada, uma vez que o narrador a conta de acordo com o público e com a situação em que se encontra a comunidade; enfim, a oralidade é contingente, contextual e inter-pessoal, enquanto que as histórias escritas “perdem” aqueles elementos. De acordo com Walter Ong,

palavras escritas são resíduo. A tradição oral não tem tal resíduo ou depósito. Quando uma história narrada com frequência não está de fato sendo narrada, tudo que existe dela é o potencial de certos humanos em contá-la... Felizmente a palavra escrita, apesar de consumir seus próprios antecedentes orais e, a menos que seja cuidadosamente monitorada até mesmo destrói sua memória, também é infinitamente adaptável. ${ }^{3}$ (ONG, 1982 apud WILENTZ, 1992, p. 65).

No campo de estudos da oralidade, os trabalhos de Ong foram influenciados por aqueles de Milman Parry (1971) e Eric Havelock (1981), que seguem linhas parecidas no sentido de identificar as influências da oralidade em textos escritos e de compreender as transições do oral para o escrito. Darnton também aponta que elementos do relato oral, como o “desempenho", não estão presentes nos textos escritos, sendo que tanto a interpretação 
existente na oralidade quanto as versões (de contos, por exemplo) que não foram escritas acabam por nos escapar (DARNTON, 1986, p. 31). Ao mesmo tempo, o autor está de acordo com aquela linha interpretativa ao dizer que os documentos escritos possuem, sim, evidências que permitem reconstruir a tradição oral. A estrutura do conto, suas características gerais, o desenrolar de sua narrativa e seus temas centrais são alguns elementos sobre os quais é possível debruçar-se para, em especial, através de comparações com outros contos, compreender um pouco daquele universo de oralidade no qual os contos eram narrados originalmente (DARNTON, 1986, p. 33).

Além disso, ao contrapor oralidade e palavra escrita, pode-se melhor compreender a primeira em oposição à segunda. Nessa direção, há toda uma série de diferenciações que se pode elencar e que foram expostas por Nicolau Sevcenko. Em linhas bastante gerais, apresentamos aqui algumas das características por ele referidas durante uma disciplina sobre história da cultura e cultura popular, ministrada na Universidade de São Paulo em 2006. De acordo com suas indicações e dos autores que apresentou, a escrita estaria ligada ao: hegemônico, individual, intelectual, contrito, controle, lei, linearidade, homogeneidade, abstração, hierarquia, verticalidade, Apolo e Byós ${ }^{4}$; ao passo que a oralidade conectar-se-ia ao: tradicional, coletivo, horizontalidade, diferenças, comunicação, corpo, sentimento, desregramento, ligação com a natureza, Pã, Dionísio e Zöe. ${ }^{5}$

Passando para o contexto africano, observamos que nele existem algumas especificidades, por exemplo, no tocante à palavra. Por se tratarem de sociedades de tradição oral, aqueles povos aos quais vamos nos referir - inseridos na chamada África Ocidental e, em especial, no atual Níger - têm uma relação específica entre a palavra escrita e a palavra falada. As formas de expressão entre aquelas sociedades são fundamentalmente orais, sendo que Mounkaïla define a palavra oral (parole) como sendo poderosa, como algo que cria acessos e soluciona problemas quando bem dita e faz mal e macula indivíduos e grupos quando mal dita (MOUNKAÏLA, 1991, p. 34). Léopold Senghor, escritor e crítico senegalês, por sua vez, também comenta a respeito do poder mágico das palavras e de sua importância para os povos que a utilizam como principal meio de comunicação, em detrimento da palavra escrita. Segundo ele, as línguas africanas estão imbuídas de imagens em suas palavras (por exemplo, o elefante é força) e de histórias em suas frases (a linguagem deve contar uma história para ser compreendida), sendo que o discurso falado é um instrumento de poder e que é através de seus símbolos que se criam ideias e ações (SENGHOR, 1983, p. 119-120). Essa compreensão vem na esteira dos estudos do contemporâneo de Senghor, o malinês Amadou Hampaté Bâ, que tratou da importância da tradição oral na África, comentando sobre a 
ligação existente entre o homem e a palavra, sobre seu valor moral, seu caráter sagrado, sobre as relações existentes entre fala, força, vida e ação, bem como sobre o poder da palavra tanto em conservar como em destruir (HAMPATÉ BÂ, 2010, p. 167-174).

É nessa direção que passa a ficar clara a importância da oralidade no contexto africano, extremamente rico em mitos, lendas, histórias e contos orais. Mounkaïla discorre a respeito dos depositários da palavra falada entre os Zarma-Songhay ${ }^{6}$ em especial, identificando nos griots $^{7}$, sacerdotes, iniciados, mulheres e velhos, além de letrados, transcritores e tradutores, os antigos e novos detentores de conhecimento a respeito de uma oralidade imemorial. Segundo a autora, através de aspectos como a interpretação, educação, memória e até criação literária, esses personagens acabam por salvaguardar aquele patrimônio oral (MOUNKAÏLA, 1991, p. 34-37).

Por sua vez, Mahamadou e Maïga buscam traços de oralidade na literatura escrita de expressão francesa de escritores africanos, no Níger em especial. Também no sentido de perpetuar o patrimônio cultural oral, tais autores fariam uso de nomes de lugares, de pessoas e de divindades, assim como expressões, traduções literais e provérbios nas línguas tradicionais dos povos de origem, de maneira a transmitir um saber. Desta forma, através da mistura do francês com as línguas nacionais nigerinas, os autores engendrariam uma aproximação entre os povos e suas culturas (MAHAMADOU ; MAÏGA, 1991, p. 96-101).

Ainda na linha da preservação cultural, vale apontar a criação do Centro de Estudos Linguísticos e Históricos pela Tradição Oral, instituído no Níger com o objetivo de, através da língua, veicular cultura e educar. O estudo das tradições orais é feito pelos participantes do Centro através de fontes como contos, poesias, canções de gesta e peças de teatro, através das quais se salvaguardam as línguas, a literatura oral e um imenso patrimônio literário, artístico, histórico, religioso, social, etc. (LAYA, 1991, p. 52-55).

Os contos orais africanos sobre os quais temos informações deslindam relações humanas, relações dos homens com a natureza e o ambiente à sua volta, além de aspectos culturais relativos a crenças e lendas, o que permite uma aproximação dos diversos povos que compõem aquele imenso continente. No contexto da Guiné (assim como o Níger, faz parte da África Ocidental), Ousmane Kaba comenta a respeito de homens se metamorfoseando em animais, fazendo referência a homens-hiena, homens-girafa, homens-leão, homens-leopardo e homens-serpente dizendo que, segundo a tradição, o poder advém da capacidade de imitação dos animais selvagens, ou seja, nas palavras do autor: "por vezes, fala-se do animal imitado como sendo o duplo do ser humano imitador. A evocação de uma besta feroz ligada ao temor 
do homem pelos poderes sobrenaturais é suficiente para semear o medo nos espíritos”» (KABA, 2006, p. 260).

Nessa direção, e no tocante à coexistência entre homem e animal, tem-se a questão da caça como um ponto de contato entre os seres e os mundos. Isso aparece em cânticos, mitos, lendas e contos nigerinos que elevam os homens que se dedicam à prática da caça; como se evidencia em um canto recolhido por Mariko a respeito do caçador, como sendo "aquele que fala e que entende todas as mensagens da natureza, dos homens, dos animais, dos vegetais, dos ventos, dos gênios, dos espíritos, dos minerais!”99 (MARIKO, 1991, p. 43). É o caçador que mantém contato com os seres do mundo invisível e do visível, com os animais que apresentam ameaça ao homem e aqueles que não apresentam. Ele seria como uma ponte entre homem e natureza. Hambaté Bâ fala da caça como uma importante escola de iniciação, "pois não há quem se aproxime imprudentemente das forças sagradas da Terra-Mãe e dos poderes da mata, onde vivem os animais” (HAMPATÉ BÂ, 2010, p. 192), e do caçador como alguém que “conhece todas as 'encantações da mata' e deve dominar a fundo a ciência do mundo animal” (HAMPATÉ BÂ, 2010, p. 192).

Como levantamos anteriormente, os narradores de contos têm o objetivo de salvaguardar a língua, a cultura e as tradições de seu povo. Através dos contos, cujas temáticas se relacionam a costumes, tradições, organização social, ritos, lendas, relações com a natureza e com o mundo invisível, entre outros, passa-se conhecimento; ou seja, aqueles diversos aspectos são transmitidos, são lembrados por aqueles que ouvem o conto e que vão, por sua vez, contá-lo a outros. Além disso, segundo alguns autores, os contos têm um caráter educativo, de trazer ensinamentos às crianças a respeito de questões sociais, de costumes e tradições do povo ao qual pertencem. De acordo com Hima, os contos são um excelente meio didático, uma vez que aspectos da ordem social e de valores são passados através deles, de maneira que as histórias e experiências dos personagens de contos funcionam como instrumento de educação. Muitas vezes os animais estão associados aos homens, sendo que é através deles que as opiniões e os ensinamentos são intercambiados: "sob a cobertura do leão, da lebre, da hiena, da aranha, o contador, a avó, apresenta instituições e comportamentos sobre os quais cada um pode se exprimir livremente" ${ }^{10}$ (HIMA, 1991, p. 40). No tocante aos personagens e às relações travadas entre eles nos contos, os animais por vezes relacionam-se a humanos, por outras não e, por outras, no caso em que aqui nos interessa, se misturam aos humanos através da metamorfose.

Propomo-nos a apresentar agora um conto compilado pela autora nigerina Fatimane Moussa Aghali (2005), cujos trabalhos estão ligados à etnolinguística e à recolha de contos 
orais do Níger. Interessada em narrativas tradicionais (folktales), a autora ouvia relatos de histórias e os transcrevia para o público europeu, em francês, divulgando contos nigerinos habitualmente passados oralmente entre as famílias e ao pé das fogueiras. Tais contos, narrados nas línguas tradicionais de povos como tuaregue, hauçá e zarma-songhay, fazem parte de seu patrimônio cultural. Além disso, remetem a aspectos como a relação daqueles povos com o mundo natural e funcionam como fonte de acesso privilegiada para compreendermos a maneira pela qual os homens da região do atual Níger, retratados naqueles contos, se relacionavam com os animais. O conto que vamos analisar se chama Les exploits d'un homme [As façanhas de um homem] e é o décimo conto do livro de Moussa Aghali intitulado Contes des dunes et des sables [Contos das dunas e das areias].

A história tem início com a conversa entre dois amigos que, em um período de fome, decidem se transformar em animais para serem vendidos no mercado. Em primeiro lugar, um deles se transforma em boi e é vendido pelo outro. Após o fim do mercado, ele se desgarra do rebanho de gado de seus compradores e, transformando-se novamente em homem, volta ao encontro do amigo, que divide com ele os lucros da venda. Em uma segunda vez, o homem se transforma em cavalo, advertindo o outro para que não o vendesse aos Songhaï. ${ }^{11}$ Entretanto, como um homem deste povo se apresenta como único comprador, a venda é concretizada. Após isso, o Songhaï comprador suspeita da natureza do cavalo que havia adquirido e o prende, advertindo seus filhos para que não o deixassem escapar. Ainda assim, o cavalo consegue fugir quando um dos meninos, intentando utilizá-lo em uma competição, acaba por soltá-lo. A partir daí, dá-se início a toda uma perseguição, que reproduzimos aqui.

Ele [o Songhaï] ainda seguia as pegadas deixadas pelos cascos do cavalo, quando se deu conta que elas tinham se transformado em passos de homem. Ele então seguiu os passos até umas cabanas abandonadas. Espiou dentro de uma delas e viu um homem que dormia profundamente. Entrou e logo pensou em se precipitar sobre o homem, mas percebeu subitamente que, em brigando com ele, sua vingança não estaria completa. Decidiu, ao invés disso, fender-lhe a cabeça com uma grande machadada. Já havia levantado seu machado para desferir um golpe mortal, quando o machado, inexplicavelmente, escapou-lhe das mãos e foi se fixar em uma parede da cabana.

O homem despertou bruscamente com o barulho do machado e transformou-se instantaneamente em uma corça veloz; pegou impulso e fugiu em um salto pela porta que havia ficado aberta. Ao mesmo tempo, o Songhaï já havia se transformado em um cachorro, que perseguiu a corça. A corça se esquivava sem esforços do cachorro furioso por hábeis desvios. Depois, a corça transformou-se em erva e o cachorro, em fogo, para queimar a erva. Dando-se conta de seu mau passo, o homem, que havia virado erva que agora queimava, transformou-se em caminho; mas o fogo transformou-se em leão e perseguiu o caminho a toda velocidade. Mas tão rápido quanto ele avançava, o homem deu-se conta de que as coisas não corriam bem e, então, ele se transformou em rio - e o leão transformou-se em água e seguiu o rio. Mas o rio transformou-se em uma árvore ressecada e o Songhaï se 
transformou em águia e pousou sobre a árvore. Para fugir da águia, a árvore transformou-se em perdiz, ao mesmo tempo em que a águia se transformava em falcão e perseguia a perdiz, dando-lhe golpes de asa e bicadas, até que os dois retornaram à aldeia, pois esse combate singular já havia durado muito tempo.

$\mathrm{Na}$ aldeia, a perdiz transformou-se em um peão de jogo de damas e caiu entre os peões de alguns aldeões que jogavam damas. O Songhaï tomou a aparência de uma das pessoas dos arredores e foi ao encontro dos jogadores, aos quais dirigiu-se neste tom:

“Com licença, senhores, mas há um peão meu que caiu entre os seus peões.”

Um dos jogadores apontou o peão que havia caído e o Songhaï disse que era de fato seu peão. Os jogadores lhe disseram:

"Escute, nossos peões são em número de doze. Conte-os e, se você encontrar um a mais, ele é seu."

O Songhaï contou treze peões. Disseram-lhe então que pegasse seu peão e que lhes deixasse continuar a partida em paz. O Songhaï pegou o peão, enfiou-o na bolsa e voltou para casa. O peão que estava dentro da bolsa transformou-se em um camundongo, começou a roer o saco e fez um buraco. Depois, o camundongo transformou-se em grãos de milho e os grãos puseram-se a cair, um após o outro, ao longo de todo o caminho. Restava apenas um grão de milho quando, pelo pior dos azares, este caiu em cima do pé do Songhaï que, imediatamente, entendeu toda a aventura. Ele olhou dentro da bolsa e a encontrou vazia. Transformando-se dessa vez em galo, ele se pôs a ciscar os grãos de milho um a um, até que chegou ao último, que se transformou, pela última vez, em gato. O gato devorou o galo e é assim que o conto chega ao fim. ${ }^{12}$ (MOUSSA AGHALI, 2005, p. 62-64).

Esta interessante história em muito se aproxima de um conto europeu, referenciado por Darnton por seu título em francês La pomme d'orange. ${ }^{13}$ Na classificação de histórias Aarne-Thompson (AARNE, 1961) ${ }^{14}$, ele é um conto de tipo 325, que segue a seguinte taxonomia: se insere na classe de "Contos de fadas", dentro da classe mais específica de “Adversários sobrenaturais” e, dentro desta, no tipo de conto denominado “Aprendiz de feiticeiro" (The Magician and his Apprentice / Le Magicien et son élève). Sob esta última classificação, dentre os diversos elementos encontrados no conto, fica priorizada a presença de um adversário que é, por sua vez, uma criatura mágica ou sobrenatural, aparecendo por vezes como um feiticeiro e, por outras, como o diabo. Entretanto, nossa intenção aqui é perceber e, além disso, priorizar outro aspecto que salta aos olhos neste conto, qual seja a transformação em animais. Como consta no livro de Darnton, o conto se passa da seguinte maneira.

Quando chega um novo bebê, o pai o vende ao diabo (um feiticeiro, em algumas versões), recebendo em troca uma despensa cheia, capaz de durar doze anos. No fim desse período, ele recebe o menino de volta, graças a um artifício que o menino concebe, porque o pequeno patife aprendeu um repertório de truques durante seu aprendizado, inclusive o poder de se transformar em animais. Antes de muito tempo, o armário está vazio e a família enfrenta outra vez a inanição. O menino, então, transforma-se em cão de caça, de modo que o pai pode vendê-lo mais uma vez ao demônio, que reaparece como caçador. Depois que o pai recebe o dinheiro, o cachorro foge e volta para casa, sob a forma de um menino. Tentam o mesmo truque de novo, com o menino transformado em cavalo. Desta vez, o demônio consegue uma coleira mágica que impede o cavalo de tornar a se transformar em menino. Mas um trabalhador rural leva o cavalo para beber num lago, dando-lhe, assim, uma 
oportunidade de fugir sob a forma de uma rã. O demônio se transforma num peixe e está prestes a devorá-lo, quando a rã se transforma num pássaro. Então, o demônio se transforma em águia e persegue o pássaro, que voa para o quarto de um rei agonizante e toma a forma de uma laranja. Então, o demônio aparece como um médico e pede a laranja, prometendo, em troca, curar o rei. A laranja derrama-se no chão, transformada em grãos de milho. O demônio se transforma num frango e começa a engolir os grãos. Mas o último grão se transforma numa raposa que, finalmente, ganha o concurso de transformações devorando o frango. (DARNTON, 1986, p. 49-50).

Impossível dizer se houve influência entre os povos para explicar a existência de contos tão parecidos e, em havendo tal influência, qual dos contos teria sido o primeiro a inspirar o outro. Não seria improvável que o contato entre franceses e povos nigerinos durante a colonização tenha proporcionado uma passagem desse conto, sendo ele, posteriormente, adaptado em contexto europeu, ou africano, dependendo de qual detivesse anterioridade. Os primeiros movimentos de colonização francesa ocorreram na região do Níger ainda em fins do século XIX (DUPEX, 1970, p. 479), tendo se efetivado de fato em 1922. Contudo, outros exploradores e viajantes estiveram naquelas regiões - ver mapa ao final deste artigo seguindo o curso do Rio Níger (que perpassa os atuais países da Guiné, Mali, Níger e Nigéria), como o escocês Mungo Park (1795-1797), que perpassou território Fulani ${ }^{15}$, Tuaregue, Zarma e do império Songhay (ALOU, 2005; SALIFOU, 1991), por volta de 100 anos antes, em fins do século XVIII. Ainda assim, por se tratar de transmissão oral, precisar uma data ou período de “criação” de um conto, seja no contexto africano, seja no europeu, torna-se extremamente difícil e, além disso, não temos sequer maiores informações sobre os contos nem o próprio conto francês em mãos. No entanto, como veremos mais à frente, talvez a discussão a respeito da influência entre os povos nem seja a questão principal a ser pensada.

Sobre o conto La pomme d'orange, Darnton o analisa a partir da questão da entrega da criança ao feiticeiro ou diabo por parte dos pais que não podem mais sustentá-la - tema que também se evidencia na história de João e Maria (Hänsel und Gretel) - e da questão do “pequeno” e pobre devorando o "grande” senhor (DARNTON, 1986, p. 50). Ao longo de seu livro, o autor tece suas interpretações a respeito de contos de fadas pelo viés das facetas da vida dos camponeses, tais como a fome, a relação entre família e trabalho, a pobreza, a dicotomia entre aldeia e estrada, a questão da esperteza e das estratégias para ver-se livre das situações de perigo ou penúria. Darnton concentra-se nos aspectos sociais vividos pelos camponeses para inserir os contos em um contexto e os interpreta à luz de tal conjuntura. Portanto, ao tratar desse conto, o autor não se concentra na questão da metamorfose.

Em relação a tudo que temos discutido até aqui, Sevcenko (SEVCENKO, 2006) comentou sobre a questão da oralidade e sua relação com os processos migratórios dos povos. 
A respeito da introdução da escrita entre aquelas populações, cujas características são a oralidade e a mobilidade, algumas descobertas foram feitas através de estudos na área da arqueolinguística e pela exploração dos mitos. O que se percebeu é intrigante: que certos temas ocorriam em lugares e entre povos completamente distintos, por exemplo, na literatura de cordel da Bahia e na literatura russa da Sibéria havia temas comuns. Essa convergência não é, necessariamente, explicada pelas ondas migratórias e pelo contato entre povos. Esse assunto foi explorado, por exemplo, por Carlo Ginzburg em relação ao fenômeno do sabá na Europa (GINZBURG, 1991), trazendo à tona as crenças e interpretações dos eclesiásticos e colocando-as frente a outras origens, mitos e extratos culturais mais antigos e populares, em um movimento que o autor denomina de “circularidade cultural”.

O tradicional e o popular estão normalmente ligados à oralidade que, por sua vez, também se relaciona com o mágico-religioso: os mitos e lendas são repassados através da fala, sendo ela o instrumento privilegiado para passar conhecimentos de iniciação e de relações diversas, como aquelas existentes entre os homens, entre homens e sua história, entre homem e natureza, entre homem e os mundos invisíveis. Dessa forma, "histórias, contos, fábulas, provérbios e máximas” (HAMPATÊ BÂ, 2010, p. 201) são as maneiras pelas quais todo tipo de conhecimento é passado entre os povos de tradição oral, notadamente - mas não só - os africanos dos quais temos tratado.

No tocante à questão dos animais, segundo Hampaté Bâ, nas tradições bambara e fulani (ou peul), existem três categorias de seres enquanto manifestações da vida na terra: os seres inanimados (areia, água, minerais, gases, etc.), os seres animados imóveis (todos os vegetais) e os seres animados móveis (animais terrestres, aquáticos e voadores), classe que também inclui o homem. Segundo o mito de origem de todas as coisas para aquelas culturas, o homem

foi feito com uma parcela de tudo o que existiu antes dele. Todos os reinos da vida
(mineral, vegetal e animal) encontram-se nele, conjugados a forças múltiplas e a
faculdades superiores. Os ensinamentos referentes ao homem baseiam-se em mitos
da cosmogonia, determinando seu lugar e papel no universo e revelando qual deve
ser sua relação com o mundo dos vivos e dos mortos. Explica-se tanto o simbolismo
de seu corpo quanto a complexidade de seu psiquismo: “As pessoas da pessoa são
numerosas no interior da pessoa”, dizem as tradições bambara e peul.” (HAMPATÉ
BÂ, 2010, p. 185).

Sevcenko (2006) discutiu questões similares ao discorrer sobre pinturas rupestres que retratavam figuras híbridas entre humano e animal. Segundo ele, tais petroglífos poderiam ser representações dos xamãs das tribos, uma criatura intermediária entre homens e animais, vivos e mortos, homens e espíritos. O xamã nunca é uma coisa só, ele é um intermediário, 
sendo aquele que permite acessar energias naturais e sobrenaturais, principalmente em momentos de fragilidade da comunidade, como tempos de guerra ou fome, por exemplo. É o xamã que faz a conexão com outros mundos de vitalidade, ele é um transportador, cujo espírito é capaz de mover-se entre os mundos visíveis e invisíveis. Essa figura do xamã, assim descrita, em muito se aproxima do que havíamos comentado a respeito do caçador, já que ambos atuam como intermediários.

Talvez se possa interpretar a questão da metamorfose por esse caminho. Por meio da transformação em animal, o homem entra em contato com a natureza, que já faz parte dele desde a origem, de acordo com a citada cosmogonia. O xamã se encontra nesse limiar, entre o mundo humano e animal, o social e o natural; mas talvez para os povos africanos a ligação com a natureza possa ser feita sem que o sujeito necessite ser um xamã ou caçador. A história do homem e do Songhay trata da metamorfose em vegetais, elementos naturais (fogo, água, etc.) e em animais, sendo que cada um possui um simbolismo específico que precisaria ser melhor estudado - como no bestiário proposto por Kaba (2006) -, inclusive para entender melhor esse conto relatado por Moussa Aghali.

Aqui podemos tecer algumas conclusões. Em primeiro lugar, pode-se pensar a questão da metamorfose no sentido de uma maneira do homem se reconectar com o mundo natural. Apesar de nosso interesse se centrar no aparecimento de animais durante as metamorfoses narradas nos contos, vegetais e outros elementos da natureza também se fazem presentes quando os humanos se transformam. A metamorfose poderia simbolizar, portanto, a aproximação do homem com Zöe, ou seja, com sua faceta que está mais ligada ao ambiente natural à sua volta. Este, por sua vez, é de alguma maneira incorporado ao homem durante a transformação, sendo através dela que o contato com Zöe é restabelecido.

Um segundo ponto parte do princípio de que a tradição oral, seja em um conto europeu, seja em um africano, é o meio preferido para transmitir conhecimentos ligados às maneiras do homem se relacionar com a natureza. Assim, podemos concluir que a comparação entre formas de expressão literária (oral!) de lugares diferentes pode servir para compreender alguns aspectos como: o mágico-religioso, a relação com o mundo natural, questões sociais ou familiares, etc. A literatura tradicional é, portanto, fonte para acessar a visão de mundo (Weltanschauung) e a relação com ele travada por parte de povos diversos e, consequentemente, melhor compreendê-los.

Portanto, podemos pensar a questão do “peixar-se” ou do “onçar-se” - relembrando as citações de Mia Couto e Guimarães Rosa -, como estando relacionada a uma (re)entrada de contato do homem com o mundo dos animais. Nas cosmogonias daqueles povos da África 
Ocidental, tal contato já estava presente no homem desde sua origem, mas como compreender o conto analisado no contexto europeu de La pomme d'orange, sem pensar na possibilidade da migração e do contato entre os povos?

Sobre este ponto, podemos concluir que aquele não deve ser, necessariamente, o foco da questão. O trabalho de verificar se houve influência entre povos diferentes acaba por deixar de lado outras questões interessantes e, além disso, os esforços na direção daquela busca podem se mostrar vãos. Talvez a metamorfose seja um daqueles temas convergentes em diferentes lugares do mundo, tal como o sacrifício e os ritos funerários, ou seja, algo referente ao humano que “ocorre” em territórios diversos e que se mostra nos contos que trabalhamos. Ao retirar o foco da questão da interferência entre povos, a comparação entre formas de expressão literária similares pode abrir portas para outros questionamentos, auxiliando a compreensão de aspectos como, por exemplo, a metamorfose em animais. 


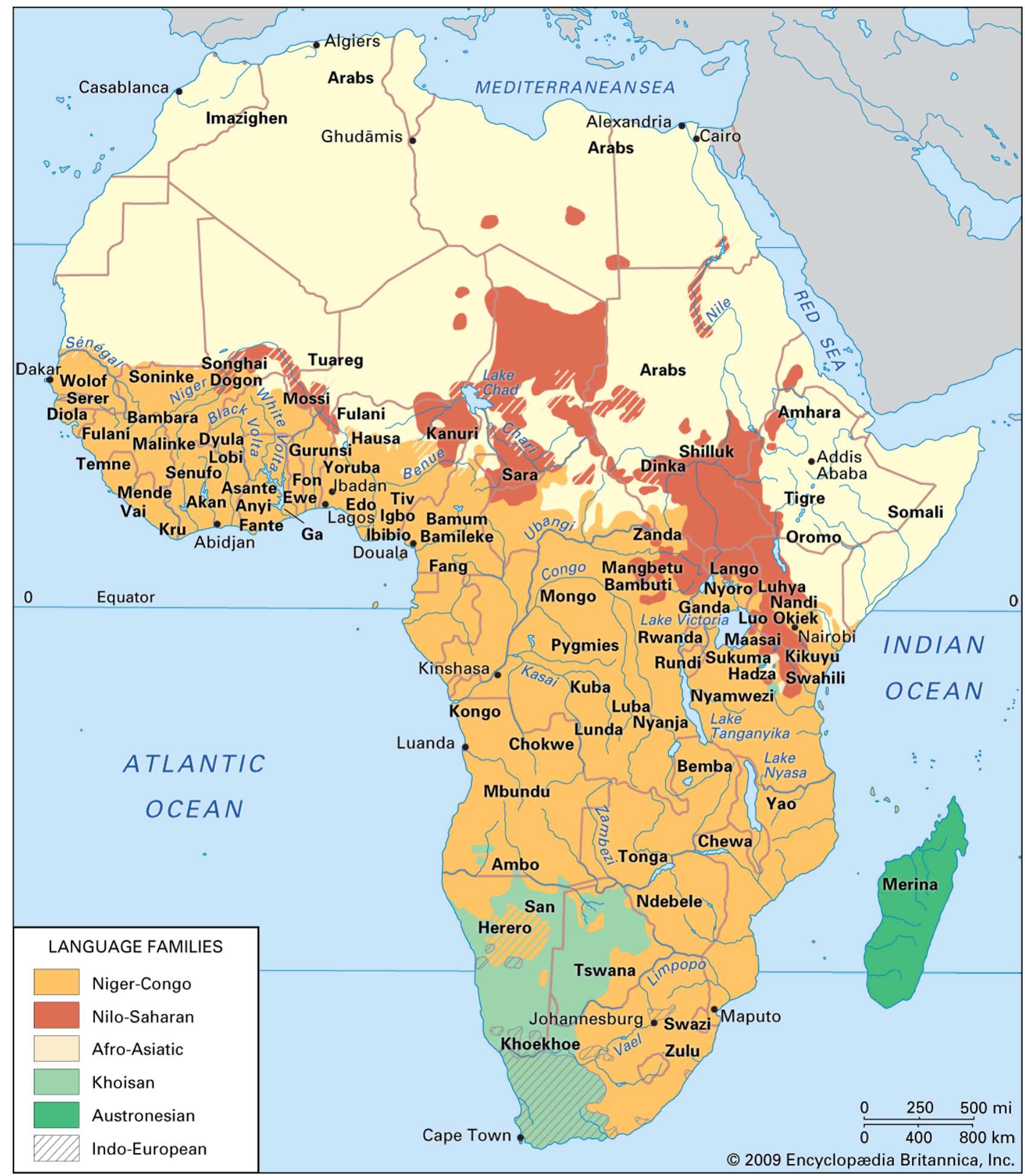

Figura 1 - Africa: languages and peoples Fonte:Britannica

\section{Referências}

AARNE, Antti. The types of the folktale: a classification and bibliography. Translated and enlarged by Stith Thompson. $2^{\text {nd }}$ rev. ed. Helsinki : Suomalainen Tiedeakatemia / FF Communications, 1961 
ALOU, Antoinette Tidjani. Editorial. Niger: emerging literature and modern orature - voicing identity. In: Tydskrif Vir Letterkunde. Vol. 42(2), 2005 . Disponível em $<\underline{\text { http://ajol.info/index.php/tvl/article/viewFile/29703/22642. }>}$

BETTELHEIM, Bruno. A psicanálise dos contos de fadas. 3. ed. Rio de Janeiro : Paz e Terra, 1980.

BRITANNICA. África: languages and peoples. Disponível em: $<$ http://www.britannica.com/bps/media-view/129695/1/0/0 > .

COUTO, Mia. Terra sonâmbula. São Paulo : Companhia das Letras, 2007.

DARNTON, Robert. O grande massacre de gatos, e outros episódios da história cultural francesa. Rio de Janeiro : Graal, 1986.

DUPEUX, Georges. La III Republique, 1871-1914. In: DUBY, Georges (Dir.). Histoire de la France. Paris : Librairie Larousse, 1970.

GINZBURG, Carlo. História noturna: decifrando o sabá. São Paulo : Companhia das Letras, 1991.

HAMPATÉ BÂ, Amadou. A tradição viva. In: História geral da África, I: Metodologia e pré-história da África / editado por Joseph Ki-Zerbo. - 2. ed. rev. - Brasília : UNESCO, 2010.

HAVELOCK, Eric A. The Literate Revolution in Greece and its Cultural Consequences. Princeton, N.J.: Princeton University Press, 1981.

HIMA, Mariama. L’éducation à travers le conte: dans la société zarma-songhay. In : VUARCHEX, François (Dir.). JACQUEY, Marie-Clotilde; PENEL, Jean-Dominique (Coord.). Littérature nigérienne, Paris, n. 107, Oct./Déc., 1991.

KABA, Ousmane. Le bestiaire dans le roman guinéen. Paris : L’Harmattan, 2006.

LAYA, Diouldé. Le CELHTO/OUA et la littérature orale. In : VUARCHEX, François (Dir.). JACQUEY, Marie-Clotilde; PENEL, Jean-Dominique (Coord.). Littérature nigérienne, Paris, n. 107, Oct/déc., 1991.

MAHAMADOU, Moussa; MAÏGA, Kanguèye Seyni. L’óralité dans la littérature écrite d'expression française. In : VUARCHEX, François (Dir.). JACQUEY, Marie-Clotilde; PENEL, Jean-Dominique (Coord.). Littérature nigérienne, Paris, n. 107, Oct/Déc., 1991

MARIKO, El Hadj Keletigui Abdourahmane. Les chants de chasseurs haoussa. In : VUARCHEX, François (Dir.). JACQUEY, Marie-Clotilde; PENEL, Jean-Dominique (Coord.). Littérature nigérienn, Paris, n. 107, Oct./Déc., 1991.

. Le Niger: diversité culturelle et linguistique. In : VUARCHEX, François (Dir.). JACQUEY, Marie-Clotilde; PENEL, Jean-Dominique (Coord.). Littérature nigérienne, Paris, n. 107, Oct/Déc., 1991. 
MOUNKAÏLA, Fatimata. Aux sources de la littérature orale : « beaux parleurs et maîtres de la parole. » In : VUARCHEX, François (Dir.). JACQUEY, Marie-Clotilde; PENEL, JeanDominique (Coord.). Littérature nigérienne, Paris, n. 107, Oct/Déc., 1991.

MOUSSA-AGHALI, Fatimane. Contes des dunes et des sables. Roissy-en-Brie: Cultures Croisées, 2005.

PARK, Mungo. Travels in the interior districts of Africa [1795, 1796, 1797]. USA : Duke University Press, 2000.

PARRY, Milman. The Making of Homeric Verse: The Collected Papers of Milman Parry, edited by Adam Parry. Oxford: Oxford University Press, 1971.

ROSA, João Guimarães. Meu tio o Iauaretê. In: . Estas estórias. Rio de Janeiro : Nova Fronteira, 2001.

SALIFOU, André. Histoire du Niger. In: VUARCHEX, François (Dir.). JACQUEY, MarieClotilde; PENEL, Jean-Dominique (Coord.). Littérature nigérienne, Paris, n. 107, Oct/Dec., 1991.

SENGHOR, Léopold Sédar. Speech and Image: an African tradition of the surreal. In: ROTHENBERG, Jerome; ROTHENBERG, Diane (Ed.). Symposium of the whole: a range of discourse toward an ethnopoetics. Los Angeles : University of California Press, 1983.

SEVCENKO, Nicolau. Notas de aula na disciplina de pós-graduação "História da Cultura e Cultura Popular: Interveniências temáticas, analíticas e conceituais”. Curso ministrado na Universidade de São Paulo (USP), 2006.

WILENTZ, Gay. Binding cultures: black women writers in Africa and the diaspora. Indiana : Indiana University Press, 1992.

\section{NOTAS}

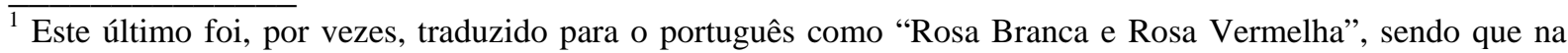
versão em inglês o conto se chama Snow-White and Rose-Red e no original alemão é Schneeweißchen und Rosenrot, sendo que o nome de "Branca de Neve" (e os sete anões) é diferente no alemão: Schneewittchen. Este conto, juntamente com "O Rei Sapo" e "A Bela e a Fera” e alguns outros contos foram enquadrados por Bruno Bettelheim no conjunto do que o autor denominou de "Ciclos do noivo-animal dos contos de fadas", sendo esta uma das partes da análise psicanalítica sobre os contos de fadas tecida pelo autor. Cf. BETTELHEIM, 1980, pp. 317-349.

${ }^{2}$ Essa questão é controversa, pois se por um lado diz-se que os Grimm recolheram relatos orais de camponeses, Darnton apresenta que eles não teriam retirado os contos da tradição oral popular, mas sim teriam compilado as histórias a partir de relatos franceses huguenotes, que por sua vez haviam bebido de fontes como Charles Perrault, de fins do século XVII. Cf. DARNTON, 1986, pp. 24-25.

3 "Written words are residue. The oral tradition has no such residue or deposit. When an often told story is not actually being told, all that exists of it is the potential in certain human beings to tell it... Fortunately literacy, though it consumes its own oral antecedents and, unless it is carefully monitored even destroys their memory, is also infinitely adaptable.” Tradução nossa.

${ }^{4}$ Na cultura grega, em linhas bastante gerais, Apolo representaria a luz, aquilo que é etéreo, que está além da materialidade, relacionando-se ao divino, ao sublime e à quintessência, é o grau máximo de perfeição. A música nas celebrações de Apolo (tocada com harpa) fala à psique, não ao corpo, é proporção, intelectualidade, dá a ideia de constrição, sem espontaneidade nem sensualidade. Ainda na cultura grega, a 
“alma” teria dois níveis, estando Byós ligada à individualidade; ela se faz de forma meditativa, pela solidão e abjuração do corpo, mais ligada ao mental e ao espiritual, sendo para este lado que o Cristianismo teria se voltado.

${ }^{5}$ Também em linhas gerais, Pã se associa ao ócio, aos prazeres, à dança, é associado às divindades tectônicas e silvestres, não ao Olimpo. Ele está ligado à natureza, é popular, rústico, sem polidez, suas festas são niveladoras, nelas todos são iguais. Pã é derrotado e morto, o que remete a Dionísio, com seu sacrifício e ressurreição; ainda assim, ambos são matrizes que tendem a se perpetuar, e ambos se perpetuam em formas de animais, como o touro, o bode e a cobra. Zöe, o segundo nível da "alma”, se relaciona de alguma forma à zoologia, sendo que cada ser é manifestação de algo contínuo, é a vida que se multiplica; ela é parte da natureza, é a vida que luta e se mantém, é imprevisível e impossível de destruir, é indomável. Para viver intensamente Zöe eram necessários rituais de exacerbação do corpo, danças, delírios, transes, possessões e a encarnação da divindade.

${ }^{6}$ Zarma-Songhay é um grupo etnolinguístico que aglutina dois povos diferentes, cujos hábitos, origens, mitos e história diferem, apesar da língua ser compartilhada. Cf. MARIKO, 1991, pp. 11-23.

${ }^{7}$ Os griots são figuras tradicionais da África Ocidental, são narradores, poetas, músicos, contadores de histórias, enfim, são uma espécie de trovador. A respeito deles, pode-se ler mais em, por exemplo, HAMPATÉ BÂ, 2010, pp. 193-200.

8 «Parfois même, on parle de l'animal imité comme étant le double de l'être humain imitateur. L'évocation d'une bête féroce liée à la crainte de l'homme aux pouvoirs surnaturels suffit pour semer la peur dans les esprits. » Tradução nossa.

9 "Celui qui parle et qui comprend tous les messages de la nature, des hommes, des animaux, des végétaux, des vents, des génies, des esprits, des minéraux! » Tradução nossa.

10 «Sous le couvert du lion, du lièvre, de l'hyène, de l'araignée, le conteur, la grand-mère, présente des instituitions et des comportements sur lesquels chachun peut s'exprimer librement. » Tradução nossa.

${ }^{11}$ Povo e grupo linguístico da África Ocidental, os Songhay chegaram mesmo a constituir um império; ver mais em ALOU, 2005 e SALIFOU, 1991. A ortografia da palavra é variada, sendo que encontramos Songhay, Songhaï, Songhoy, Songhä, Songhai, Songai, Sonrhaï. A forma "Songhay” é a que aparece na maior parte dos textos que utilizamos, mas aqui optamos por manter a forma "Songhaï” por ser a utilizada por Moussa Aghali em seu livro. Não localizamos nenhuma variação em dicionários de língua portuguesa.

12 Il suivait encore les empreintes laisées par les sabots du cheval quand il s'aperçut qu'elles s'étaient transformées en pas d'homme. Il suivit alors les pas jusq'aux masures abandonées. Il jeta un coup d'oeil dans l'une d'entre elles et vit un homme qui dormait profondément. Il entra et songea tout d'abord à se précipiter sur l'homme, mais il réalisa en un éclair qu'en se battant avec lui sa vengeance ne serait pas complète. Il décida plutôt de lui fendre la tête d'un grand coup de hache. Il avait donc levé sa hache pour lui en asséner un coup mortel, mais la hache lui échappa inexplicablement des mains et alla se ficher dans une paroi de la masure.

L'homme se réveilla brusquement au bruit qu'avait fait la hache et il se transforma instantanément en une biche véloce, prit son élan et s'enfuit d'un bond par la porte restée ouverte. Dans le même temps, voilà que le Songhaï s'était transformé en chien qui poursuivit la biche. La biche esquivait sans efforts le chien furieux par d'habiles crochets. Puis la biche se transforma en herbe, et le chien en feu pour brûler l'herbe. Se rendant compte de sa méprise, l'homme devenu herbe qui brûlait se transforma en chemin, mais le feu se transforma en lion qui poursuivit le chemin à toute vitesse. Mais aussi vite qu'il avançât, l'homme se rendit compte que ses affaires ne s'arrangeaient pas, et alors il se changea en rivière, et le lion se transforma en eau et suivit la rivière. Mais l'autre se transforma en arbre desséché, et le Songhaï se transforma en aigle et se posa sur l'arbre. Pour fuir l'aigle, l'arbre se transforma en perdrix, tandis que l'aigle se transformait en épervier qui poursuivit la perdrix, lui donnant des coups d'aile et de bec, jusqu'à ce que tous deux se retrouvent au village, car ce combat singulier avait duré fort longtemps.

Au village, la perdrix se transforma en pion de jeu de dames et chut parmi les pions du jeu de villageois en train de jouer. Le Songhaï prit l'apparence d'une des personnes alentour et vint trouver les joueurs auxquels il s'adressa sur ce ton :

«Excusez-moi, Messieurs, mais il y a un pion à moi qui est tombé parmi vos pions. »

L'un des joueurs lui montra du doigt le pion qui avait chut, et le Songhaï dit que c'était bien son pion. Les joeurs lui dirent :

"Écoute, nos pions sont au nombre de douze. Compte-les, et si tu en trouves un de plus, il est à toi. »

Le Songhaï compta treize pions. On lui dit alors qu'il prenne son pion et qu'il les laisse continuer leur partie en paix. Le Songhaï prit son pion, le fourra dans son sac et rentra chez lui. Le pion qui était dans le sac se changea en souris, commença à ronger le sac et fit un trou. Puis la souris se changea en grains de mil et les grains se mirent à tomber l'un après l'autre tout le long du chemin. Il ne restait plus qu'un seul grain de mil quand, par la pire des malchances, celui-ci tomba sur le pied du Songhaï qui comprit à l'instant toute 
l'aventure. Il regarda dans le sac et vit qu'il était vide. Il se transforma cette fois-ci en coq qui se mit à picorer les grains de mil un à un, jusqu'à ce qu'il arrive au dernier qui se transforma une dernière fois en chat. Le chat dévora le coq, et c'est ainsi que le conte s'achève. (Tradução nossa.)

${ }^{13}$ A tradução do nome deste conto é complexa, uma vez que remete a um tipo específico de maçã (pomme), chamada pomme d'orange, aparentemente natural da região da Bretanha (noroeste da França), como também parece remeter a um costume de se receber uma laranja (orange) como presente de Natal. Atualmente, há um festival de inverno em Peillac (região da Bretanha) chamado La Pomme d'Orange, que se centra em música, dança, narração de histórias, gastronomia e "artes da oralidade". Uma pesquisa mais aprofundada a respeito do título do conto deveria ser feita para melhor compreendê-lo e a seu contexto.

${ }^{14} \mathrm{O}$ catálogo de Aarne-Thompson, bem como um esquema de tipos de contos segundo um catálogo francês, podem ser encontrados neste site: http://afas.revues.org/319\#tocto1n5

Por sua vez, a Universidade de Pittsburgh compilou, por ordem alfabética de tema e seguindo a tipologia de Aarne-Thompson (quando esta se aplica), títulos de contos de diversos países, que estão disponibilizados neste site: http://www.pitt.edu/ dash/folktexts.html

${ }^{15}$ A palavra utilizada para se referir a esse povo é variada, podendo ser "fulani” (em inglês, normalmente), "fula” (em português, normalmente), "peul” (em francês, normalmente), entre outras variações. Por vezes o povo é referenciado por diversos dos termos em sequência. 